\title{
Evaluation of Surgico-therapeutic Management in Obstructive Urolithiasis without Cystorrhexis in Male Cattle-Calves
}

\author{
Rakesh Pooniya*, Suresh Kumar Jhirwal, Rajesh Saini, Suresh Kumar Palsania, \\ Anil Kumar and Mohan Patel
}

\author{
Department of Veterinary Surgery \& Radiology, College of Veterinary and Animal Science, \\ Bikaner, Rajasthan University of Veterinary and Animal Sciences (RAJUVAS), Bikaner, \\ Rajasthan, India \\ *Corresponding author
}

\section{A B S T R A C T}

\begin{tabular}{l}
\hline K e y w o r d s \\
Urolithiasis, \\
Abdominal \\
distension, Tube \\
cystostomy, \\
Urine acidifiers \\
\hline Article Info \\
$\begin{array}{l}\text { Accepted: } \\
\text { 18 May 2020 } \\
\text { Available Online: } \\
\text { 10 June } 2020\end{array}$ \\
\hline
\end{tabular}

The study was conducted on twelve $(n=12)$ clinical cases of obstructive urolithiasis in male cattle calves with intact urinary bladder presented to the Department of Veterinary Surgery \& Radiology, RAJUVAS, Bikaner. The diagnosis was made on the basis of history and clinical signs (anorexia, depression, bilateral abdominal distension and concretions at urethral orifice). All the animals needed surgical intervention for passive routes for passage of urine till bladder healing occurred and urine continued to pass through normal urethral orifice. The animals were divided into two groups depending on the surgical intervention adopted viz., Tube cystostomy $(n=6)$, Perineal urethrostomy $(n=6)$. Haemoglobin was found to be below; BUN and serum creatinine above the normal reference values in majority of the cases. Obstructive urolithiasis occurred more frequently under specific managemental condition like heavy concentrate feeding along with higher mineral concentration ground water intake. The overall survival rate was higher in animals treated by tube cystostomy than perineal urethrostomy. Urine acidifiers like ammonium chloride and sodium chloride and herbal litholytic agents like Cystone tablet were effective in dissolution of urinary calculi.

\section{Introduction}

India has largest livestock population in the world. It has about 190.9 million cattle, which is 37.28 per cent of total livestock population in India (NDDB, 2017). India ranks first in milk production. This data indicates the importance of cattle and buffaloes in Indian economy. Male calves are usually weaned at an early age as compared to female calves. Also, male calves are offered concentrate, particularly oilseed cake instead of a calf starter or weaning ration. Thus, a high protein diet with no milk and very low water intake leads to formation of urinary calculi (Bhatt et al., 1973). 
Obstructive urolithiasis means the formation of calculi in urinary tract with subsequent urinary blockage (Radostits et al., 2000). It appears to affect both the sexes equally but urinary blockage is more common problem in male animals. Male ruminants are more likely to be affected because of an extremely long and narrow urethra, in contrast to females having a shorter and wider urethra (Matthews, 1999). Steers are most commonly affected by obstructive form of disease because of the anatomical conformation of urinary tract (Larson, 1996; Radostits et al., 2000). Urinary calculi formation usually results from a combination of nutritional, physiological and managemental factors. It is mainly attributed to imbalanced or excessive intake of minerals (McIntosh, 1978; Radostits et al., 2000). A calcium phosphorous imbalance results in high urinary phosphate excretion which is an important factor in formation of phosphate calculi. Less frequent types of uroliths include those composed of silica, oxalates or carbonates (Larson, 1996). Retention of the urine is one of the important surgical disorders resulting due to formation of urinary calculi in kidney, ureter, urinary bladder and urethra associated with considerable morbidity and mortality. Urine retention is frequently observed in young cattle calves even at the age of 1-3 months resulting in uraemia and death. Urolithiasis frequently occurs between the age of 2-6 months in bovine calves (Fazili and Ansari, 2007). Treatment of obstructive urolithiasis has been found to vary depending upon clinical status of animal and duration of urinary obstruction (Larson,1996).Medical treatment has been described with marginal success in relieving the obstruction during early stages of the disease (Crookshank, 1970). However, once urethral obstruction is complete, surgical intervention becomes warranted (Haven et al., 1993). Obstructive urolithiasis in ruminants, especially in cattle, is of considerable economic importance as losses inflicted by this malady are considered very high (Singh and Singh, 1990).

\section{Materials and Methods}

The present study was conducted on 12 clinical cases of retention of urine in cattle calves of less than one year of age presented to the Clinics of Department of Veterinary Surgery and Radiology, Bikaner (Rajasthan). History of cases regarding age and sex of the animal, duration of illness, feeding pattern, managemental practices, early signs of disease, previous treatment etc. were obtained from the owner. The diagnosis was confirmed on the basis of history, clinical examination, abdominal palpation and abdomino-centesis as per case status. Venous blood samples were collected for estimation of different haematological and biochemical parameters. Abdominocentesis was done at slightly dorsal and caudal to the umbilicus with the help of a 16 or $18 \mathrm{G}$ hypodermic needle and variable amount of blood tinged fluid was drained out. Fluid therapy (normal saline), broad spectrum antibiotics and supportive therapy (antiinflammatory and analgesic drugs) were given to the animal with severe dehydration or uraemia as per the requirement of the case.

\section{Surgical management of obstructive urolithiasis}

Animals were subjected to tube cystostomy and perineal urethrostomy. Preoperatively, fluid and supportive therapy were given to animals suffering from severe dehydration or uraemia as per the requirement of the clinical cases. All the animals were operated under epidural anaesthesia and local infiltration of left paramedian area starting from the rudimentary teats.

\section{Tube cystostomy}

This surgery was performed in dorsal recumbency. Animals were shaved at an area 
lateral to the penis on the left side of the abdomen near the rudimentary teat. After proper scrubbing of surgical area, incision was given anterior to the rudimentary teat. After incising the skin, subcutaneous tissue, fascia, muscles and peritoneum, urinary bladder was located. After locating the urinary bladder, a direct deep nick incision was given by Baird Parker blade No.20 parallel to the surgical incision line through which the Foley's catheter was passed with pointed end towards the incision. Cystorrhaphy was done using catgut no.1 after placement of catheter inside the urinary bladder. The catheter was inserted and the bulb of the catheter was inflated with about $30 \mathrm{ml}$ the normal saline solution to fix the catheter in the urinary bladder and anchored to the skin near prepuce. After successful lodging of the catheter into the urinary bladder, the peritoneum, muscles and skin were closed in routine manner.

\section{Perineal urethrostomy}

In this technique animals were given epidural anaesthesia employing $2-5 \mathrm{ml}$ of two per cent lignocaine hydrochloride. Once staggering of both hind limbs commenced following epidural anaesthesia, animals were secured in dorsal recumbency. The perineal region of midline between scrotum and little below to the anus was aseptically prepared by shaving, scrubbing with dettol soap and application of povidone iodine solution. A $2-5 \mathrm{~cm}$ long incision was given on midline commencing from neck of scrotum to $2-5 \mathrm{~cm}$ upward. After dissecting through fascia the sigmoid flexure was exteriorised by manually. The retractor peni muscle was resected away from penis. A partial penectomy was done at the level of sigmoid flexure and urethra was split up to 1$3 \mathrm{~cm}$ length. Proximal stump was ligated properly using catgut no.1 suture material. PVC catheterisation was done in animals from urethrostomy stump to urinary bladder.
The newly created penile stump was transfixed at lower commissure of incision with stay suture. The skin incision was closed with simple interrupted suture with silk. A retrograde hydropulsion was done with 50$100 \mathrm{ml}$ of normal saline in order to ensure restoration of urine out flow.

\section{Postoperative management}

Post-operative treatment included antibiotics (streptomycin and penicillin combination)@ $1.25 \mathrm{gm}$ total dose $\mathrm{i} / \mathrm{m}$ in cattle calves for five days, non-steroidal anti-inflammatory drug (meloxicam @ $0.5 \mathrm{mg} / \mathrm{kg}$ body weight i/m for three days) and ammonium chloride @ 100 $\mathrm{mg} / \mathrm{kg}$ body weight, b.i.d. orally for twenty days. Fluid therapy (normal saline) was continued intravenously for 1-3 days as per requirement of the case. Cystone (Himalaya Drug Company, India) tablets (2-4 tablets twice a day for fifteen days) were given orally to prevent reoccurrence of the condition. Owners were advised to add sodium chloride to the drinking water @ 3-4 per cent to enhance frequent water intake and aid in acidification of urine. Local antiseptic dressing with five per cent povidone iodine (betadine) was advised daily for a week. The blocked catheters were cleaned by flushing with normal saline solution.

\section{Haemato-biochemical parameters}

For the estimation of haemato-biochemical studies, $10 \mathrm{ml}$ blood was collected in each animal from jugular vein using sterile syringe and stored in sterile vial containing EDTA. 5 $\mathrm{ml}$ fresh blood sample as used for the study of haematological parameters and rest of the sample $(5 \mathrm{ml})$ was centrifuged immediately to separate out the serum, which was preserved for further analysis. The haematological parameters such as haemoglobin $(\mathrm{Hb})$ by Sahli's hemoglobinometer, total leucocytic count (TLC) by Haemocytometer and 
differential leucocytic count (DLC) by using Giemsa's staining were estimated from the fresh blood sample as per standard technique. Blood urea nitrogen (BUN) in $\mathrm{mg} / \mathrm{dl}$ and serum creatinine (Sr.Cr.) in $\mathrm{mg} / \mathrm{dl}$ were also estimated by using IDEXX auto analyser at TVCC, RAJUVAS, Bikaner.

\section{Results and Discussion}

The clinical signs exhibited by the cases with intact urinary bladder included straining for urination and kicking at belly (83.33\%), concretions encrustation at urethral orifice and restlessness $(75 \%)$, mild bloat $(66.67 \%)$, grinding of teeth $(41.66 \%)$ and swelling on ventral abdomen $(25 \%)$.

The age of the calves varied from 1-12 months (mean age 4 months).

\section{Tube cystostomy}

This surgical procedure was done in sex cases. The time of completion of surgical procedure was around 30-40 minutes. Dribbling of urine from the external urethral orifice in the treated animals started after 7-8 postoperative days and free flow of urine started after 8-9 postoperative days. Foley's catheter dislodgement and loss were observed in one animal.

Postoperative follow up of tube cystostomy up to three months revealed that five cases were survived and were voiding normal urine flow from urethral orifice. In one case, complications were recorded in which flushing with normal saline solution was done after that they recovered successfully.

\section{Perineal urethrostomy}

This surgical technique was performed in six animals having intact urinary bladder.PVC catheterisation was done in six animals from urethrostomy stump to urinary bladder. Indwelling PVC catheter was removed after sixteen postoperative days and skin sutures after ten days. In five out of six case perineal urethrostomy was successful and these animals were recovered uneventfully where as one animal was found died on $8^{\text {th }}$ postoperative day.

\section{Evaluation of surgical procedure}

All the cases that were included in this study were treated by two surgical procedures viz. tube cystostomy and perineal urethrostomy.

The evaluation of these surgical procedures was done on the basis of postoperative complications like catheter loss, catheter dislodgement, catheter blockade, free flow of urine, healing of surgical wound, requirement of second surgical intervention and survival rate.

\section{Catheter blockade}

The problem of blockage of catheter were reported one each in cases treated by tube cystostomy and perineal urethrostomy. The blockade of catheters in these cases was corrected by flushing with normal saline solution postoperatively as and when required.

\section{Catheter loss and dislodgement}

Foley's catheter was lost in one animal that was treated by tube cystostomy technique on $4^{\text {th }}$ postoperative day respectively.

\section{Requirement of second surgical intervention}

One case which was treated by tube cystostomy required second surgical intervention. 
Time for removal of catheter intube cystostomy and urethral catheter

The mean time for removal of catheter in tube cystostomy and perineal urethrostomy was 13.66and 15.6 days respectively.

\section{Recovery/ success rate}

In present study, overall success rate was 91.66 per cent $(11 / 12)$. The cases which were treated by tube cystostomy recorded success rate of 100 per cent, in the cases which were treated by perineal urethrostomy the success rate was 83.33 per cent. The percentage of recovered animal without any complication was 83.33 per cent $(5 / 6)$ in cases which were

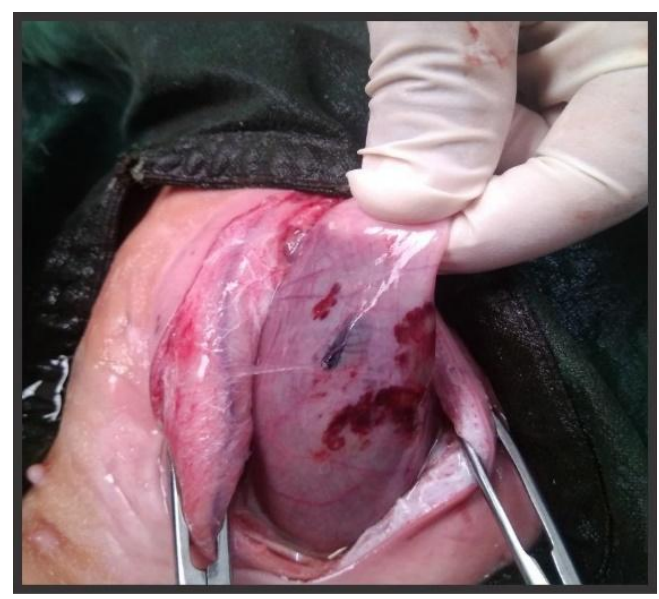

Fig.1 Ruptured Urinary Bladder

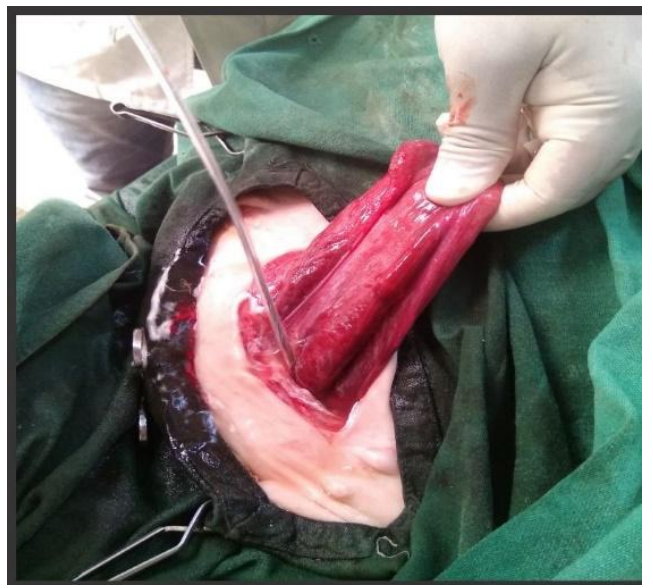

Fig.3 Exteriorisation of UB for cystorraphy treated by tube cystostomy, eighty per cent $(4 / 5)$ in cases which were treated by perineal urethrostomy.

\section{Hematobiochemical parameters}

Values of haemoglobin ranged from 5.40$11.80 \mathrm{gm} / \mathrm{dl}$. Average haemoglobin was found to be $8.77 \pm 0.29 \mathrm{gm} / \mathrm{dl}$. In most of the animals, haemoglobin values were found below normal range (ref.11.12 \pm 1.21 ). Total leucocyte count in ranged from 3.20-15.25 thousand $/ \mathrm{mm}^{3}$. Mean total leucocyte found to be $6.69 \pm 0.47$ thousand $/ \mathrm{mm}^{3}$. In most of cases of total leucocyte count was within normal range (4.5-13.8 thousand $\left./ \mathrm{mm}^{3}\right)$.

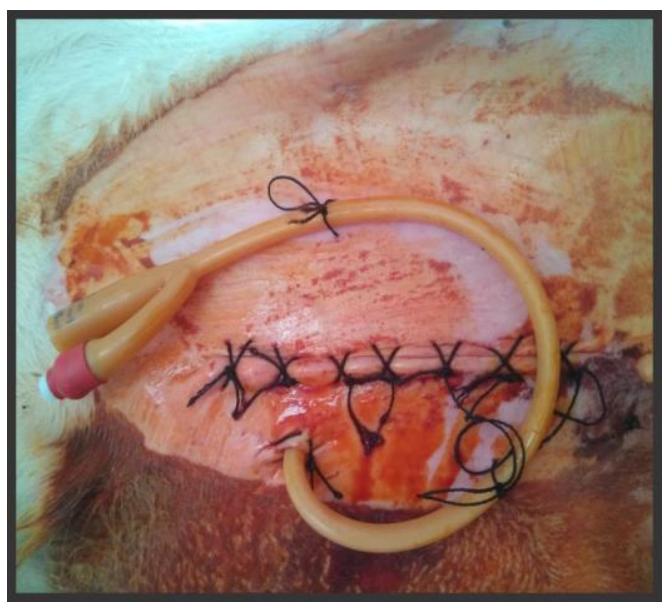

Fig.2 Placement of Foley's catheter

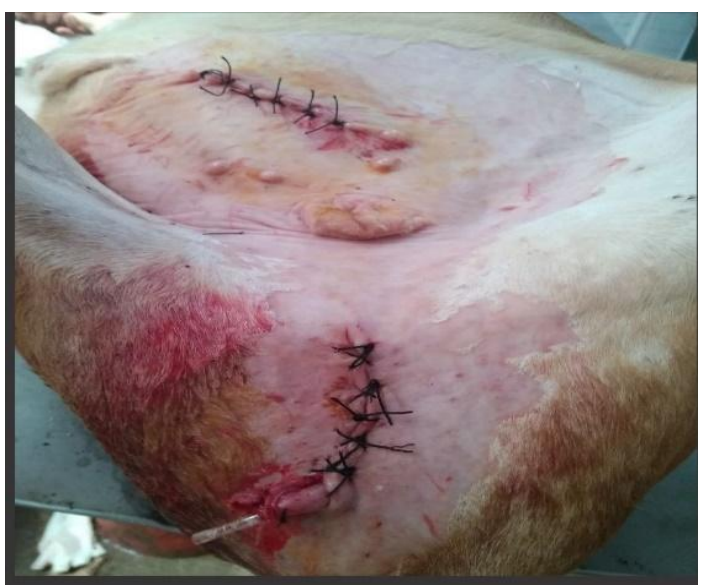

Fig.4 Incision Sites for Cystorrhaphy with urethrostomy 
In two cases TLC values were found to be above 13.8 thousand $/ \mathrm{mm}^{3}$, which was above than normal reference value. In two cases, TLC values were found to be below 4.5 thousand $/ \mathrm{mm}^{3}$, which was below than normal reference value. Blood urea nitrogen value in serum of affected cattle calves ranged from 17-94 $\mathrm{mg} / \mathrm{dl}$. Mean BUN was found to be $50.51 \pm 3.13 \mathrm{mg} / \mathrm{dl}$. These values were found to be above the normal range $(6-27 \mathrm{mg} / \mathrm{dl})$. The elevated base values of BUN recorded in ten clinical cases. Serum creatinine values ranged from $0.98-6.40 \mathrm{mg} / \mathrm{dl}$. Mean value of serum of the serum creatinine was found to be $2.47 \pm 0.23 \mathrm{mg} / \mathrm{dl}$. Most of the clinical cases were reported with the higher values of serum creatinine (normal range: 1-2 $\mathrm{mg} / \mathrm{dl}$ ). The elevated base values of serum creatinine in nine clinical cases.

Monocytes ranged from $1-12 \%$. The mean value of monocytes was found to be $4.74 \pm 0.38 \%$. These were found to be $1-3 \%$ and $4-12 \%$ in four and eight animals, respectively. The values were found close to the reference value $(5.10 \pm 0.99 \%)$ in most of clinical cases of present study. Eosinophils ranged from $0-6 \%$. The mean value of eosinophils was found to be $1.74 \pm 0.27 \%$. However, the values were found to be $1-3 \%$ and $4-6 \%$ in ten and two animals. The mean values were found below to reference value $(3.82 \pm 0.71 \%)$ in most of clinical cases present study. Neutrophils ranged from $18-81 \%$. The mean value of neutrophils was found to be $40.22 \pm 1.83 \%$ (reference value: $28.91 \pm 1.21 \%$ ). Base values of DLC showed slight neutrophilia in eleven clinical cases. This indicates activation of defence system of the body in response to the condition like uroperitoneum due to urinary bladder rupture. Lymphocyte value ranged from 15-69\%. The mean value of lymphocyte was found to be $51.94 \pm 2.27 \%$. Base values of DLC showed slight lymphocytopenia in ten clinical cases. The mean values were found to be lower than reference value $(62.23 \pm 3.10 \%)$ of lymphocytes. Basophils were found zero percentage in all clinical cases.

In the present study, history taken from owners revealed that most of the clinical cases were maintained on concentrate ration like cotton seed cake, groundnut cake and grains. Wang et al., (1997) reported more incidence of obstructive urolithiasis in animals fed high grain diet with $\mathrm{Ca}$ : $\mathrm{P}$ ratio as low as $1: 1$. In this study, most of the cattle calves brought for treatment belonged to rural areas and were also maintained on high grain diet as a milk replacer because availability of green fodder was less in these area.From the findings of present study, it is evident that the feeding habits have a profound predisposing effect on the development of particular uroliths. The incidence of obstructive urolithiasis was mostly found in early winter to end of winter under temperate conditions, pointing towards the inadequate water intake and lack of green fodder as another predisposing factor for the development of uroliths. Kopper (1967) and Muhee (2006) also recorded highest number of cases of urolithiasis in calves during winter season. In the present study calves of age group between 1-3 months had the highest $(42.85 \%)$ occurrence of obstructive urolithiasis, followed by the calves of 4-6 months $(28.57 \%)$, 7-9 months $(20 \%)$ and 1012 months (8.57\%). Amarpalet al., (2004) also recorded a high incidence of obstructive urolithiasis in buffaloes and caprines below 6 months of age. Muhee (2006) also recorded highest incidence (27.27\%) of obstructive urolithiasis in the calves of 3-4 months age followed by 4-5 months age group (19.32\%) and lowest (10.23\%) in 1-2 months age group. The elevated base values of BUN recorded in twenty cases of present study. These findings were in agreement with those of Villar et al., (2003). Sharma et al., (2006) also reported an elevated values of BUN in obstructive urolithiasis due to the onset of acute renal 
failure manifested by a decreased glomerular filtration rate as a result of back pressure on the kidneys and absorption of these substances from the urine present in the urinary bladder in the intact urinary bladder cases, or from peritoneal cavity in the ruptured urinary bladder cases of complete obstructive urolithiasis. The findings of elevated Serum creatinine in present study were in consonance with the findings of Gera and Nigam (1981) and Villar et al., (2003). Kerr (2002) also reported that serum creatinine levels elevated more quickly than urea levels at the start of the disease, and also decreased more quickly when an improvement takes place, thus this could be used for early diagnosis and recovery from the disease. The all survival rate $(100 \%)$ was higher in animals treated by tube cystostomy in present study. Parrah et al., (2014) and Mangotraet al., (2017) also reported the similar finding in cases of surgical management of obstructive urolithiasis.

In all the animals of present study ammonium chloride and 3-5 per cent sodium chloride supplementation were given after surgery. Bailey (1967) and Radostits et al., (2007) also advocated supplementation of sodium chloride and ammonium chloride as these increased the water intake and increases the solubility of urolith. Herbal litholytic agent (Cystone tablets) was most commonly practiced as first line treatment for management of obstructive urolithiasis in present study. Joshi et al., (1988) also reported Cystone tablets decreased the super saturation and $\mathrm{pH}$ of urine as a result of its diuretic activity.

In conclusions, obstructive urolithiasis occurred more frequently under specific managemental condition like heavy concentrate feeding with higher mineral concentration in ground water. The overall survival rate was higher in animals treated by tube cystostomy in present study. Urine acidifiers like ammonium chloride and sodium chloride, and herbal litholytic agents like Cystone $^{\circledR}$ tablet were effective in dissolution of urinary calculi.

The disease can be prevented to a large extent by modifying the prevailing managemental practices i.e. feeding of concentrate and roughage in proper ratio, encouragement of more water intake and advised to add sodium chloride to the drinking water @ 3-4 per cent to enhance frequent water intake.

\section{References}

Amarpal., Kinjavdekar, P., Aithal, H.P., Pawde, A.M., Pratap, K. and Singh, T. 2004. Incidence of urolithiasis: A retrospective study of five years. Indian Journal of Animal Sciences. 74(2): 175-177.

Bailey, C.B. 1967. Silica excretion in cattle fed a ration predisposing to silica urolithiasis: Total excretion and diurnal variations. American Journal of Veterinary Research. 28(127): 1743-1749.

Bhatt, G.A., Ahmed, S.A. and Prasad, B. 1973. Studies on incidence and physiological chemistry of urinary calculi in bovines. Indian Veterinary Journal. 50: 459-464.

Crookshank, H.R. 1970. Effect of ammonium salts on the production of ovine urinary calculi. Journal of Animal Sciences. 30: 1002-1004.

Fazili, M.R. and Ansari, M.M. 2007. Prevalence of bovine obstructive urolithiasis in Kashmir valley. Indian Veterinary Journal. 84: 540-541.

Gera, K.L. and Nigam, J.M. 1981. Biochemical and haematological studies following retention of urine due to urolithiasis in bullocks. Indian Veterinary Journal. 58(5): 403-406.

Haven, M.L., Browman, K.F. and Engle, T.A. 1993. Surgical management of urolithiasis in small ruminants. Cornell Veterinarian. 83: 47-55.

Joshi, P.K., Patil, D.B., Sukumaran, K., 
Parsania, R.R. and Patel, M.R. 1988. Effect of Cystone on urine crystallization in bullocks. Indian Journal of Veterinary Surgery. 9(1): 18-20.

Kerr, M.G. 2002. Veterinary Laboratory Medicine Clinical Biochemistry and Haematology. Blackwell Science Ltd.

Kopper, S.A. 1967. Relation between successfull treatment of cases of retention of urine in bullocks and the position of the calculi. Gujarat Veterinarian. 1: 58.

Larson, B.L. 1996. Identifying, treating and preventing bovine urolithiasis. Veterinary Medicine. 91: 366-377.

Mangotra, V., Singh, K. and Proch, A. 2017. Tube cystostomy in male buffalo calves suffering from retention of urine. Journal of Animal Research. 7(2): 279-291.

Matthews, J. 1999. Diseases of the Goat. Blackwell Science Inc. Malden, MA.

Muhee, A. 2006. Prevalence and clinical management of obstructive urolithiasis in cattle calves. Thesis submitted to SKUAST of Kashmir for the partial fulfilment for the award of MVSc degree.

McIntosh, G.H. 1978. Urolithiasis in Animals. Australian Veterinary Journal. 54: 267271.

N.D.D.B. 2017. Livestock population in India by species. $w w w . n d d b . o r g$.

Parrah, J.D., Moulvi, B.A., Gazi, M.A., Makhdoomi, D.M., Athar, H., Hamadani, H. and Khan, Q.A. 2014. Evaluation of different surgical techniques for the management of bovine obstructive urolithiasis. Journal Veterinary Science \& Technology. 5(5): 1-5.
Radostits, O.M., Blood, D.C., Gay, C.C, and Hinchcliff, K.W. 2000. Veterinary Medicine: A Textbook of the Diseases of Cattle, Sheep, Pigs, Goats and Horses. Bailliere Tindall, London. pp: 493-498.

Radostits, O.M., Gay, C.C., Hinchcliff, K.W. and Constable, P.D. 2007. Disease of bladder, ureters and urethra. In: Veterinary Medicine; A Text Book of the Disease of Cattle, Horses, Sheep, Pigs and Goats. $10^{\text {th }}$ edition. Saunders Elsevier. Pp: 565.

Sharma, P.D., Singh, K., Singh, J. and Kumar, A. 2006. Bacteriological, biochemicaland histopathological studies in uroperitoneum in buffalo calves (Bubalusbubalis). Indian Journal of Animal Sciences. 76(2): 124-126.

Singh, J. and Singh, K. 1990. Obstructive urolithiasis and uraemia in cattle and buffalo- A review. Indian Journal of Veterinary Surgery. 11: 1-20.

Villar, D., Larson, D.J., Janke, B.H., Schwartz, K.J., Yaeger, M.J., Carson T.L. and Blaylock, R. 2003. Case reportObstructive urolithiasis in a feedlot steer. The Bovine Practitioner. 37(1): 74-77.

Wang, X., Huang, K., Gao, J., Shen, X., Lin, C. and Zhang, G. 1997. Chemical composition and microstructure of urolithiasis and urinary sediment crystals associated with the feeding of high-level cotton seed meal diet to water buffalo calves. Research Veterinary Science. 62(3): 275-280.

\section{How to cite this article:}

Rakesh Pooniya, Suresh Kumar Jhirwal, Rajesh Saini, Suresh Kumar Palsania, Anil Kumar and Mohan Patel. 2020. Evaluation of Surgico-therapeutic Management in Obstructive Urolithiasis without Cystorrhexis in Male Cattle-Calves. Int.J.Curr.Microbiol.App.Sci. 9(06): 2260-2267. doi: https://doi.org/10.20546/ijcmas.2020.906.276 